\title{
Management of Brinjal Fruit and Shoot Borer (Leucinodes orbonalis Guenee) in Nepal
}

\section{Manish Gautam*, Sagar Kafle, Bamdev Regmi, Gopal Thapa and Susan Paudel}

Agriculture and Forestry University, Nepal

*Corresponding Author: Manish Gautam, Agriculture and Forestry University, Nepal.

Received: July 10, 2019; Published: August 27, 2019

DOI: 10.31080/ASAG.2019.03.0632

\begin{abstract}
Eggplant (Solanum melongena) is one of the most important vegetables of South Asia including Nepal, India, Bangladesh, Srilanka, Pakistan, Thailand and other several nations of the world. Brinjal Fruit and Shoot Borer (Leucinodes orbonalis Guenee) is regarded as the key pest of Brinjal and it causes extremely heavy losses to the farmers. It causes significant damage to the plant; up to $80 \%$ damage to fruits has been identified. This situation has posed a hindrance to the farmers in commercial cultivation of eggplant, hence relevant literatures were collected, studied and reviewed regarding biology and management of borer. Existent management practices are not being enough to control the population of this pest and in such condition it is necessary to have a holistic approach towards Integrated Pest Management practices. In this article, several control measures for L. orbonalis including resistant varieties, cultural methods, physical and mechanical barriers, sex pheromones, bio-pesticides and bio-control agents; chemical and botanical means are outlined and evaluated with supportive facts and figures with reference to previous works and researches in this area.
\end{abstract}

Keywords: Brinjal Fruit and Shoot Borer; Integrated Pest Management (IPM); Insecticide; Bio-Control Agents

\section{Introduction}

Solanum melongena, Eggplant (Brinjal), is one of the most economically important vegetable crops in South Asia, South East Asia including Nepal, India, Pakistan, Srilanka, Bangladesh, Thailand, Philippines, Cambodia, and Laos. It holds ample significance as a vegetable crop in Terai and Mid-hill of Nepal since it can be grown in variety of soil and can be cultivated throughout the year. Generally, it is grown in Terai and Mid-Hill region during Bhadra-Asoj (August-September) and Magh-Falgun (February-March) respectively. Brinjal is a Kharif season crop in Nepal and mostly thrives best during long summer season with optimum temperature of $20^{\circ} \mathrm{C}-30^{\circ} \mathrm{C}$ for growth and fruit development.

In Nepal, Brinjal cultivation is still non-commercial in most parts of the nation and further research on its pests and pathogens are yet to be carried out. Several insects like Fruit and Shoot Borer, White fly, Leaf hopper, Thrips, Mites, Leaf Roller, Red Spider Mite etc. are found to cause loss in Brinjal in different parts of the world. The key pest of Brinjal; Brinjal Fruit and Shoot Borer (Leucinodes orbonalis) are responsible for causing huge damage to the growth and development of stems, young sprouts, buds and fruits as well. This insect can also attack other vegetables of solanaceae family (alternate host) and results in severe losses. Larvae bore inside the fruit and reduce its yield up to 70\% - 75\% [1-3]. This larva of this insect has unique nature of feeding on monophagous diet aided by homing and tunneling behavior which ultimately enables the adult insect to face the challenges of chemical pesticides as well making it difficult to manage the insect population in the standing crops. It causes reduction of the yield as well as reduced content of vitamin C up to $80 \%$ [4]. The losses caused by this pest may vary from season to season. This is because moderate temperature and high humidity favour the population build-up of Brinjal Fruit and Shoot Borer and cause heavy losses during hot and humid condition [5,6].

In Nepal, mostly chemical insecticides are applied indiscriminately by the farmers to control this insect. Many farmers also practice homebased control measures and biological control methods such as Ashes, Cow Urine, Marigold barriers and so on. However, farmers are not able to control the infestation completely and the measures incur more production cost than actual profit obtained from them. Thus, it is utmost important to control this pest and this can be achieved only through a systematic management approaches. The strategy or management approaches include use of resistant varieties, cultural methods, physical and mechanical barriers, sex pheromones, bio-pesticides and bio-control agents, botanical and chemical means of management included in a whole package of Integrated Pest Management (IPM) strategy.

\section{Methodology}

Pertinent data were collected with consultation of journal articles, research articles, proceedings, annual reports, thesis, review reports, survey reports, library books etc. covering the insect biol- 
ogy, damage and management practices with supportive facts and an extensive review was done. The data and findings were evaluated and arranged orderly and finally summarized with conclusive outlines.

\section{Insect Biology}

The Brinjal fruit and shoot borer (BFSB), Leucinodes orbonalis (Lepidoptera: Pyrallidae) is one of the most important destructive pests of Brinjal and is reported to cause huge losses to the Brinjal and other solanaceaus vegetables. Leucinodes orbonalis was described and classified by Guenee in 1854 . The scientific name of the Brinjal Fruit and Shoot Borer is Leucinodes orbonalis Guenee.

The taxonomic classification of Brinjal Fruit and Shoot Borer is as follow

\section{Phylum: Arthropoda \\ Class: Insecta \\ Order: Lepidoptera \\ Family: Crambidae (Syn: Pyralidae) \\ Genus: Leucinodes \\ Species: Orbonalis \\ Scientific name: Leucinodes orbonalis Guenee}

L. orbonalis Guenee is practically monophagous, feeding principally on eggplant; however other plants belonging Solanaceae (Tomato, Chilly etc) are also reported to be hosts of this pest. It is the most important, destructive pest and the first ranked pest of Asian region like India, Pakistan, Srilanka, Nepal, Bangladesh, Thailand, Philippines, Cambodia, Laos and Vietnam [7]. It is mostly distributed in those areas having hot and humid climate [8].

L. orbonalis has four growth stages: egg, larva, pupa and adult out of which larval period is the longest, followed by pupal and then incubation period lasts. Oviposition usually takes place during the night time. The female adult lays around 80 to 253 eggs $[9,10]$; eggs are laid singly on the lower surface of the young leaves, green stems, flower buds, or calyces of the fruits. The eggs are laid in the early hours of the morning singly or in small batches on the ventral surface of the leaves (CABI, 2007). The shape of the eggs is flat, elliptical and the diameter is $0.5 \mathrm{~mm}$. The egg colour is creamywhite at the time of laying but change to red prior to hatching [11]. The incubation period varies as per summer or winter and it is 35 days in summer and 7-8 days in winter and later hatch into dark white larvae after completion of incubation period. The larval period lasts for 12 - 15 days during summer season and 14 - 22 days during winter season (Rahman, 2006). There are at least five instar stages of the larvae [12] while six instar stages have also been reported $[13,14]$.

The newly hatched larva usually bores into the petioles, midrib of large leaves and young tender shoots at the vegetative stage. During reproductive phase, the larvae bore into the flower buds and also enter into the susceptible fruits through the calyx [15]. The fruits which are infested can be easily identified by observing the boring holes where dark colour excreta can be easily seen. Larvae bore and make their way inside plant shoots and fruits and adversely affect the plant growth ultimately causes loss in the yield and fruit quality, and thus make the vegetables unfit for human consumption.

\section{Insect habit and nature of damage}

The Brinjal fruit and shoot borer larva bores into the nearest tender shoot, flower, or fruit of eggplant within one hour of hatching and then plug the entrance hole with black colored excreta. Caterpillars make tunnels and bore inside the petioles and midribs of large leaves of young plants and the affected leaves may drop off ultimately [16].

Larva feeds inside the shoots and leaves of the plants which results in wilting of the young shoots. The presence of wilted shoots is the surest sign of damage by this pest and we can know the infestation of BFSB. The damaged shoots ultimately wither, become flaccid type and drop off. This causes reduction in the development and growth of the plant, reduced fruit number and size. Similarly, there is delayed crop maturity and the newly formed shoots and leaves are also subjected to larval damage. The damaged fruits are unfit for market and thus this pest causes huge loss to farmers under heavy infestations.

Larva feeds inside the fruit which destroys fruit tissue. It is practically monophagous and principally feeds on eggplant however, tomato (Lycopersicon esculentum), potato (Solanum tuberosum), selected nightshades (S. nigrum and S. indicum), and turkey berry (S. torvum) which are regarded as the alternate hosts of this pest.

\section{Management practices}

\section{Resistant varieties}

Resistant varieties are considered as the first line of defense against pests and one of the safest methods which are compatible with other control measures. Several attempts have been made to cultivate resistant genotype of Brinjal against $L$. orbonalis, but no cultivars with appreciable resistance have been developed so far. In Nepal, Very few researches and breeding techniques have been practiced to develop a resistant genotype suitable for its geography. However many research activities are being done in other nations to search for true resistant cultivar of Brinjal against this pest. Thin fruits, short with lower number of calyx, Shoots with small diameter and thin stems and branches are the tolerant characters of a resistant genotypes (Malik., et al. 1986). The plants with long and narrow fruits and long hairs on the shoots prevented the insect to lay eggs on the shoot and fruits. Such characters are of major preference while researching on resistant cultivars of Brinjal for L. orbonalis. Eggplant accessions EG058, BL009, ISD 006 and 
Turbo (a commercial hybrid) are found to have substantial level of resistance to L. orbonalis as reported by Srinivasan R [17]. Local cultivars like Pusa Purple Long - 74 and Navkiran were found to be promising varieties in semi-arid region of Rajasthan and they had low shoot and fruit infestation as well [18]. In a field screening of different genotypes of Brinjal, Thapa., et al. [19] discovered that this pest was found in highest density in F1 long and F1 round hybrids but other popular varieties like Nurki, Neelam Long and Pusa Purple Long were the least preferred genotypes in Nepal. Among the tested genotypes, Nurki, Neelam Long and Pusa Purple Long were least damaged and low infestation was seen due to L. orbonalis. NARC [20] reported that Pusa Kranti and Nurki varieties of Brinjal were least infested than Pusa Purple Long (PPL) and proved to be even better than local landraces.

\section{Use of sex pheromones}

Sex pheromones are considered as important IPM component and they are widely used to monitor and mass-trap the male insects of several crops. The use of sex pheromones in Brinjal attracted several adult male moths and reduced the adult population of $L$. Orbonalis [21]. The major component of BFSB sex pheromone was identified and synthesized in laboratory was (E)-11-hexadecenyl acetate (E11-16: Ac) in China [22]. the compound was used at the rate of 300-500 and was tested for its efficacy in Sri Lanka. However, the synthetic product was inferior and less effective to live virgin female moths [23]. But, the high number of male moths were trapped by the combination of (E)-11-hexadecenyl acetate and (E)11hexadecen-1-ol and significantly reduced the pest damage in India and Bangladesh $[8,11,17,24]$. The use of pheromone traps was found effective in reducing shoot damage and fruit infestation with 46.15 percent protection and 25.6 percent protection over control respectively [21]. In field conditions, Delta traps and funnel traps are also useful for luring adult moths by using sex pheromones and this can also help in reducing the infestation of adult insect. However, the trap design, trap location and the height of the location of the trap greatly influenced the number of insects attracted to the traps. Dutta., et al. [25], from his experiment in field condition found that the use of pheromone trap starting from 15 days after transplanting till final harvest gave substantial protection in shoot damage (58.39\%), fruit damage (38.17\%) and $49.71 \%$ increase in yield over control [25]. Thus, the use of sex pheromones is one of the most important methods in controlling L. orbonalis [21].

\section{Cultural and mechanical methods}

Cultural practices like crop rotation, intercropping, pruning and removal of alternate hosts are important crop management practices to obtain better yield and reduce pest infestation to some extent. Alternate hosts like Potato, Tomato, Chilly and other vegetables of Solanaceae family should be removed from the periphery of Brinjal field since they provide shelter to L. orbonalis and provide suitable environment for the growth and development of the insect [26]. Brinjal stubbles and remains of previous season crop serve as suitable site for egg laying and growth of this insect $[27,28]$. Removal of stubbles and alternate host are proved to be effective to minimize the spread of this pest. Similarly, pruning of infested twigs and branches, removal of unwanted plants, reducing the highly dense population and removing wilted plant parts help in preventing the spread of L. orbonalis [29]. Since pruning and pinching have no negative effects on the growth and development of Brinjal, the wilted damaged shoot should be periodically pinched or pruning should be done. They must be collected and buried or burned to reduce pest infestation [30-32] The damaged eggplant shoots and fruits should be removed by different ways at regular intervals without disturbing the healthy fruits and shoots and minimizing the spread of the pest which can help in reducing the pest infestation to great extent [17].

Suitable nylon net barrier at suitable heights are also frequently used by the farmers for commercial cultivation of Brinjal which helps to keep the adult insects away from the cultivated field [20]. It is always advised to combine two or more methods of protection such as use of barriers combined with manual destruction of the pest significantly reduced the damage than any single methods [11]. When use of barrier + clipping practices was followed instead of using barrier alone, highest marketable fruit yield as well as lowest fruit infestation for number and weight was obtained [32]. Kaur., et al. [33] reported BH-1, BH-2 and Punjab Barsati cultivars had significantly higher marketable fruit yield and total fruit yield in net house condition than any other varieties. So, mechanical barrier can also be regarded as one of the most efficient technologies of $\mathrm{L}$. orbonalis management and it has resulted better management of pest population too.

\section{Bio-pesticides, bio-control agents and botanical pesticides}

Bio-pesticides, Bio-control agents and Botanical pesticides are the most eco-friendly approach of IPM and a good control measure against $L$. orbonalis. They have minimum effect on non-target organisms and very little effect on human health. Several bio-control agents like Bacteria, Nuclear Polyhydrosis Viruses (NPV), Fungi (Beauveria bassiana) are tested against this pest in Brinjal. According to Ajit., et al. [34], lowest mean shoot infestation was seen by the use of Bacillus thuringiensis (13.31\% shoot infestation) and Neem oil $(15.05 \%$ shoot infestation) respectively. At the same time, $M$. anisoplae (15.1\% shoot infestation) and B. bassiana (15.37\% shoot infestation) were at par with each other. They were also significantly superior over untreated control plots with as high infestation as $25.68 \%$. The use of Neem recorded minimum fruit infestation of $16.36 \%$ while M. anisoplae, B. thuringiensis and B. bassiana were not so effective treatments for fruit infestation but all of them were superior over untreated control plots $(35.23 \%$ fruit infestation). Among the bio-pesticides, lowest shoot and fruit infestation was seen by the foliar application of Bt @ $2 \mathrm{~g} /$ litre of water along with the highest marketable yield followed by NSKE (5\%) [35]. The 
most effective treatments was the application of 5\% NSKE because it was able in reducing the whitefly and shoot and fruit borer infestation on Brinjal when applied in different spray schedule. The same treatment also recorded maximum yield of Brinjal [36].

Similarly, although the efficacy of NPV is lower, it can be used as a bio control agent [32]. There are many biocontrol agents available to use for crops against insects because of their host specific and crop specific nature and it is found that sixteen parasitoids, three predators and three entomo-pathogenic species are reported as natural enemies of L. orbonalis from all over the world [37]. Among all of these bio control agents, Trichogramma chilonis Ishii is demonstrated as the most effective and it is an egg parasitoid which attacks the egg stage of the target pest [38]. In Nepal, endoparasitoids, such as Camptothlipsis sp., Campyloneurus mutator Fabricius, Chelonus sp. and Cremastus (Trathala) flavoorbitalis (Cameron) (Hymenoptera) etc have been identified as natural enemies of the BFSB [39]. The Botanical oil products were also found to be efficient for management of BFSB. When Brinjal was cultivated as Kharif and Rabi Crop in different seasons, Neem oil @ 2 percent was the best treatment in both condition with $60.2 \%$ and $59.91 \%$ reduced damage respectively supporting the previous results of many researchers. This result was followed by Nimbecidine @ 2 $\mathrm{ml} /$ litre with $57.42 \%$ reduced damage [40].

All the botanicals, such as Ecogold @ $10 \mathrm{ml} /$ litre of water; Alata soap @ $5 \mathrm{~g} /$ litre of water etc were reported to reduce the pest infestation to significant degree. Further, other botanicals such as Garlic @ 30 g/litre of water; Neem oil @ 3 ml/l of water; Papaya leaves@92 g/litre of water and Wood ash @ $10 \mathrm{~g} /$ plant were also tested in different research activities and they turned out to produce significant result in terms of reduction of pest population of Brinjal Fruit and Shoot Borer including other pest of Brinjal [41]. Similarly, Endosulfan with 14.23 percent fruit damage, both iluppai oil and pungam oil were significantly effective in controlling shoot and fruit borer with 15.93 percent and 16.3 percent fruit damage respectively [21]. MD. Islam A 2013 showed that Neem leaf extract @50 g/L water was highly effective against L. orbonalis. Many workers previously have reported the efficacy of different biocontrol agents and botanical pesticides against this pest which can help to minimize the pest damage and increase yield significantly.

\section{Use of chemical insecticides}

Farmers rely exclusively on the use of synthetic insecticides in order to combat the pest [3]. Ghimire 2001 reported that farmers apply insecticides 10-12 times in winter and 25-30 times or even more in summer or rainy season. This is due to the increase in activity of L. orbonalis during warm and humid season. The trend of using insecticides with can cause development of pest resistance and environmental contamination (Kabir., et al. 1996). However, insecticides are the only measures practiced to control this pest in commercial cultivation of Brinjal.
Many workers have reported the efficacy of insecticides in controlling the fruit and shoot borer of Brinjal throughout the world. Spinosad, Fenvalerate, Emamectin Benzoate, Chlorpyriphos, Cypermethrin, Carbofuran, Carbosulfan, Aldicarb granules, Phorate, Dimethoate, Carbaryl, Malathion etc are frequently used as control measures and sprayed in different concentration and combinations. Azadirachtin 0.003\% EC (Multineem, Nimbecidine), Emamectin benzoate 5\% SG, Cypermethrin 25\% EC and Fenvalerate $20 \%$ EC have been recommended against this pest (Krishi Diary, MOA). The experiments using chemical pesticides revealed the effectiveness of Flubendiamide, Spinosad and Chlorfenapyr against L. orbonalis respectively in reducing the infestation on eggplant and it eventually led to increase in yield. Similarly, the overall damage caused by the pest was also reduced by the application of Emamectin Benzoate, Methoxyfenozide and Bacillus thuringiensis along with increment in the yield of Brinjal [42].

Three sprays of Chlorpyriphos + Cypermethrin @ 0.01 percent a.i. in 15 days intervals resulted in minimum shoot infestation of $2.15 \%$ and $12.95 \%$ fruit infestation. It was followed by alphamathrin@ 0.01 percent a.s. and the highest marketable yield of 87.77 q/ ha was also obtained from application of alphamathrin. Sharma., et al. 2012 suggested that the combination of Chlorpyriphos 50\% $\mathrm{EC}+$ Cypermethrin $5 \% \mathrm{EC}$ can be utilized as a valuable chemical component in Integrated Pest Management for L. orbonalis in eggplant crop.

Emamectin Benzoate (0.002\%) and Endosulfan (0.05\%) demonstrated superior results in terms of reduction of infestation of shoot and fruit in Brinjal followed by Novaluron in case of shoot infestation (7.00) [43]. According to Anwar S., et al. [44], the pest population was suppressed when Emamectin benzoate was applied and lowest mean percent of fruit infestation $40.1 \%$ was recorded after its application. It was followed by Cypermethrin with $40.43 \%$ fruit infestation. Awal., et al. [45] found that Tracer-45 SC(Spinosad), Bactoil, Proclaim-5 SG demonstrated significantly higher mortality against 4 th instar larvae of BSFB while Tripura., et al. 2017 reported from his experiment that Chlorantraniliprole is the best insecticides among treatments for effective management of Brinjal shoot and fruit borer followed by Spinosad. Similarly, The fruit infestation by number basis revealed that the treatment Chlorantraniliprole excelled all other treatments; the other best treatment Spinosad was at par difference with it; on weight basis, the Chlorantraniliprole and Spinosad significantly $(p<0.01)$ excelled over all other treatments in regards of attaining lower fruit infestation and maximum protection; the highest marketable yield (32.03 mt/ha) was recorded on Chlorantraniliprole treated plots with 34.39 percent increase in yield over untreated check followed by Spinosad, Abamectin, Karanjin, Tozen, respectively [3]. Most of the works on the use of insecticides reveals that the most effec- 
tive insecticides are Chlorantraniliprole, Emamectin benzoate, Spinosad followed by other insecticides.

Although the use of these insecticides excelled other methods of control, these insecticides left some unwanted negative effects leading to the reduction of natural enemies of L. orbonalis, increased pest resistance and resurgence, environmental pollution and severe impacts on human health. There could be chemical residue after the use of chemical pesticides in an unsafe manner as such residue of Malathion, Parathion, Fenitrothion 0.64, 0.36 and $0.64 \mathrm{ppm}$ respectively was found in fresh Brinjal sale in the market [46]. Similarly, many people also died in Nepal recently due to Excessive Chemical pesticides in vegetables. Thus, the use of insecticides should be followed with extreme precautions and only if other methods become ineffective in controlling the pest. However, chemical pesticides along with IPM practices can prove to be very effective than using any methods alone.

\section{Integrated pest management practices (IPM)}

IPM is the integrated practice method which includes all of the methods to control the pest. For L. orbonalis, no single practice can be considered effective and thus only integrated management can bring effective result in its control and management. Successful adoption of IPM in Brinjal cultivation can ensure sustainable cultivation practice and helps in preservation of environment and less negative impacts on human health. It includes the use of sex pheromones, physical and mechanical barriers, pruning and pinching practices, bio-control and bio-pesticides and other chemical insecticides for effective control and management of pest.

Chakraborty [47] demonstrated the efficient model of IPM strategy based on the yield performance. According to him, the efficacy of first one is the highest and lowers on later. The most effective models of IPM as per him are:

- Flubendiamide together with NSKE, NLE, Deltamethrin + Trizophos

- application of new molecule of Rynaxypyr, NLE, NSKE, Chlorpyriphos

- NSKE, Emamectin Benzoate, NLE, Chlorpyriphos, Neem and Oil.

The fruit damage was significantly reduced when corianderintercropping was practiced in eggplant (antifeedant) (Satpathy and Mishra, 2011). It was also found that integration of phytosanitation, application of Neem Seed Kernel Extract (NSKE) and mechanical control had significant impact on the incidence and damage of BFSB [48]. The IPM treatment involved withholding of all pesticide use, weekly clipping of damaged shoots, and installation of sex pheromone for mass trapping of male adults showed that the fruit infestation in IPM plots was much less in pesticide spray (check) plots [11]. Sharma., et al. [49] reported that the combined treatment including pesticides, botanicals and cultural methods resulted lower shoot and fruit damage as well as the fruit yield was also increased.

Similarly, the module with three different component as per Dutta., et al. [25], viz. pheromone trap, mechanical control and application of Peak Neem (neem based insecticide) was the best and reduced the shoot damage, fruit damage and also increased the yield. Endosulfan + Deltamethrin $(0.07 \%, 0.0025 \%)$ and Endosulfan + Fenvalerate $(0.07 \%+0.005 \%)$ were highly effective against BFSB and $13.3 \%$ damage was recorded while $69.8 \%$ damage was seen in control [50]. The use of chemical pesticides in IPM was not practiced initially but the judicious use of pesticide was accepted globally.

IPM includes combination of different management practices and it is proved that combined tactics are far more effective than single measure against the pests. However, one must consider the compatibility and cost benefit ratio of these practices when applying for commercial cultivation.

\section{Conclusion}

Brinjal Fruit and Shoot borer (L. orbonalis Guinee), is a monophagous insect that mainly feeds on Brinjal and other vegetables of solanaceae family. Due to its short life cycle and boring nature, it heavily infests on the Brinjal plants and it has resulted huge losses in several nations of the world including Nepal. The management of this insect is of utmost importance to increase the yield of Brinjal and other solanaceae vegetables. The successful management of this pest can be brought about only by effective IPM practices. Several researches have already proved that using any one of the methods is not sufficient to completely minimize the loss due to $L$. orbonalis. Using the resistant cultivars is the farmer's first line of defense. However, no cultivars have been yet successively tested to have effective resistance against this insect. Still, Nurki, Neelam Long and Pusa Purple long are the most suitable varieties with few tolerance against these insects.

Similarly, cultural, mechanical and biological periodic pruning of infested twigs and branches, practices like intercropping, adopting net barriers, alternate hosts removal, and the use of sex pheromones can have mild effects on the pest population and damage reduction to some extent. If these practices can be effectively applied for commercial cultivation, they can also help significantly in reducing the pest infestation in Brinjal and can minimize the potential losses.

However, farmers are more attracted to use the chemical insecticides intensively to control the borer. The intensive use of such insecticides has caused negative harm to the environment and has residual effect to human beings upon consumption. Despite, we cannot neglect their efficacy and use in the control and manage- 
ment of fruit and shoot borer. Among large number of pesticides, Chlorantraniliprole, Emamectin benzoate, Spinosad and Cypermethrin are widely used and most effective respectively according to the researches. Apart from chemical pesticides bio-pesticides like Neem oil and Neem Leaf extract have great effectiveness against L. orbonalis. Botanical oils and extract of different plants such as Neem, Pungam, Iluppai etc. are found to be very effective against the pests and insects. Biocontrol agents such as Bacillus thuringiensis, Trichogramma chilonis which is an egg parasitoid and larval parasitoid-Trathala flavo-orbitalis (Cameron) can also be utilized as means of potential parasitoids of this pest since they also show significant result in the reduction of shoot and fruit damage of Brinjal by BFSB. However, none of these methods alone are able to fully suppress the pest. So we should focus our practices on IPM which is sustainable and has no negative impacts on the environment and human beings. Several combinations of practices involving cultural and mechanical methods, chemical methods and biopesticides can prove to be more effective than practicing any one of these methods alone.

\section{Bibliography}

1. MD Islam A. "Evaluation of Plant extracts for the management of Brinjal shoot and fruit Borer". Department of Entomology, Sher-e-Bangla Agricultural University (2013).

2. Dhandapani N., et al. "Bio-intensive pest management in major vegetable crops: An Indian perspective". Journal of Food, Agriculture and Environment 1.2 (2003): 330-339.

3. RP Mainali., et al. International Journal of Applied Sciences and Biotechnology 3.4 (2015): 727-730.

4. Sharma DR. Bio-efficacy of certain insecticide and biopesticides against major pest of brinjal under field condition. M. Sc. Thesis, Indian Agriculture Research Institute, New Delhi, India, (2002): 160.

5. Shukla A and Khatri S N. "Incidence and abundance of brinjal shoot and fruit borer Leucinodes orbonalis Guenee". The Bioscan 5.2 (2010): 305-308.

6. Bhushan S., et al. "Efficacy and economics of pest management modules against brinjal shoot and fruit borer (Leucinodes orbonalis)". The Bioscan 6.4 (2011): 639-642.

7. AVRDC Eggplant entomology. Control of eggplant fruit and shoot borer. Progress Report. Asian Vegetable Research and Development Center, (AVRDC), Shanhua, Taiwan (1994): 88.

8. Srinivasan R. Insect and mite pests on eggplant: a field guide for identification and management. AVRDC Publication No. 09-729. AVRDC - The World Vegetable Center, Shanhua, Taiwan. (2009): 64.
9. Taley YM., et al. "Bionomics of brinjal fruit and shoot borer, (Leucinodes orbonalis Guenee)". Punjabrao Krishi Vidyapeeth Research Journal 8.1 (1984): 29-39.

10. Alpuerto AB. "Ecological studies and management of brinjal fruit and shoot borer, Leucinodes orbonalis Guenee". Indian Journal of Agricultural Sciences 52.6 (1994): 391-395.

11. Alam SN., et al. "Development of an integrated pest management strategy for eggplant fruit and shoot borer in South Asia". The World Vegetable Center.

12. Atwal AS. "Agricultural pests of India and Southeast Asia". Kalyani Publishers. New Delhi, India. (1976): 529.

13. Baang LA and Corey FM. "Life history of an eggplant fruit and shoot borer, Leucinodes orbonalis (Guenee) (Lepidoptera: Pyralidae)". Chiang Mai University Journal of Science 4.1 (1991): 45-61.

14. FAO. Eggplant integrated pest management an ecological guide. FAO inter-country programme for integrated pest management in vegetables in South and Southeast Asia. Bangkok, Thailand. (2003): 177.

15. Netam M., et al. "Screening of Shoot and Fruit Borer (Leucinodes orbonalis Guenee.), for Resistance in Brinjal (Solanum melongena L.) Germplasm Lines". International Journal of Current Microbiology and Applied Sciences 7.2 (2018): 3700-3706

16. Butani DK and MG Jotwani. Insects in vegetables. New Delhi: Periodical Expert Book Agency. (1984): 356.

17. Srinivasan R. "Integrated Pest Management for eggplant fruit and shoot borer (Leucinodes orbonalis Guenee) in south and Southeast Asia: past, present and future". Journal of Biopesticides 1.2 (2008): 105-112.

18. Mathur A., et al. "Management of Brinjal Shoot and Fruit Borer: Dilemma of Adopting Bt Brinjal over Integrated Pest Management Technology". International Conference on Clean and Green Energy IPCBEE 27 (2012).

19. Thapa RB., et al. "Field screening of selected brinjal genotypes against shoot and fruit borer, Leucinodes orbonalis Guenee (Pyralidae: Lepidoptera) in eastern terai of Nepal". Journal of Institute of Agriculture and Animal Science 30 (2007): 173-177.

20. NARC. NARC Research Highlights 1989/1990 to 1994/1995. Nepal Agricultural Research Council, Khumaltar Lalitpur, Nepal (1998). 
21. Mathur A., et al. "Field evaluation of plant products and microbial formulations against brinjal shoot and fruit borer, Leucinodes orbonalis Guenee under semi-arid conditions of Rajasthan". Journal of Biopesticides 5.1 (2012): 71-74.

22. Zhu P., et al. "Identification of the sex pheromone of eggplant borer Leucinodes orbonalis Guenee (Lepidoptera: Pyralidae). Zeitschrift Fur Naturforschung C". A Journal of Biosciences 43 (1987): 1347-1348.

23. Gunawardena N.E., et al. "The sex pheromone of the brinjal pest, Leucinodes orbonalis Guenee (Lepidoptera): problems and perspectives". Journal of the National Science Council of Sri Lanka 17.2 (1989): 161-171.

24. AVRDC Annual Report. Asian Vegetable Research and Development Center. Shanhua, Taiwan. (1996): 46-49.

25. Dutta P., et al. "Management of brinjal fruit and shoot borer, Leucinodes orbanalis Guenee in agro-ecological condition of West Tripura". Scholarly Journal of Agricultural Science 1.2 (2011): 16-19.

26. Murthy PN and Nandihalli BS. "Crop loss estimation caused by Leucinodes orbonalis Guenee in potato". Pest Management in Horticultural Ecosystem 5.6 (2003): 225-242.

27. Rahman MM., et al. "Evaluation of combined management options for managing brinjal shoot and fruit borer". Academic Journal of Entomology 2.2 (2009): 9298.

28. Satpathy S and Mishra DS. "Use of intercrops and antifeedants for management of eggplant shoot and fruit borer Leucinodes orbonalis (Lepidoptera: Pyralidae)". International Journal of Tropical Insect Science 31.1-2 (2011): 52-58.

29. Neupane FP. Integrated management of vegetable pest (Nepali language). Centre for Environmental and Agricultural Policy Research Extension and Development (CEAPRED), Bakhundol, Lalitpur, Nepal (2000): 172.

30. Rao TV and Rao MK. "Incidence and control of brinjal pest". Andhra Agricultural Journal 2.2 (1995): 76-85.

31. Som MG and Maity TK. Brinjal. In: Bos TK and Som MG (eds.) Vegetable Crops in India. Naya Prakashan Publisher, Calcuttia, India. (1986) :293-342.

32. Ghimire SN. Eco-frendly management of brinjal fruit and shoot borer, Leucinodes orbonalis Guenee (Lepidoptera: Pyralidae). M. Sc. Ag. Thesis, Department of Horticulture, IAAS, Rampur, Chitwan, Nepal. (2001): 80.

33. Kaur S., et al. "Management of brinjal shoot and fruit borer, Leucinodes orbonalis Guenee through net house cultivation". Annual Review of Entomology 43 (1998): 243-270.
34. Ajit Tripura., et al. "Biorational management of brinjal shoot and fruit borer (leucinodes orbonalis guenee) in mid hills of Meghalaya". Journal of Entomology and Zoology studies 5.4 (2017): 41-45

35. Nayak US., et al. "Comparative efficacy of some bio-pesticides and botanicals against brinjal shoot and fruit borer, Leucinodes orbonalis Guenee". Journal of Interacademicia 17.1 (2013): 39-43.

36. Mandal S., et al. "Efficacy of synthetic and botanical insecticide against whitefly (Bemiciatabaci) and shoot and fruitborer (Leucinodes orbonalis G.) on brinjal (Solanum melongena L.)". Journal of Crop and Weed 6.1 (2010): 49-51.

37. Khorsheduzzaman., et al. As many as sixteen parasitoids, three predators and three species of entomopathogens have been reported as natural enemies of L. orbonalis from all over the world (1998).

38. Krishnamoorthy A. "Exploitation of egg parasitoids for control of potential pests in vegetable ecosystems in India". Comunicata Scientiae 3.1 (2012): 1-15.

39. Kafle GP. "New records of some insects and non-insects parasites of Leucinodes orbonalis Guenee in Nepal". Nepalese Journal of Agriculture 5 (1970): 99-103.

40. Murugesam N and Murugesh T. "Bioefficacy of some plant products against brinjal fruit borer, Leucinodes orbonalis Guenee (Lepidoptera: Pyrallidae)". Journal of Biopesticides 2.1 (2009): 60-63.

41. Mochiah MB., et al. "Botanicals for the management of insect pests in organic vegetable production". Journal of Entomology and Nematology 3.6 (2011): 85-97.

42. Chatterjee ML and Mondal S. "Sustainable management of key lepidopteran insect pests of vegetables". Acta Horticulturae 958 (2012).

43. Sharma A and Sharma PC. "Bioefficacy of insecticides against Leucinodes orbonalis on brinjal". Journal of Environmental Biology 31.4 (2010): 399-402.

44. Anwar S., et al. "Efficacy of insecticides against infestation of brinjal fruit borer, Leucinodes orbonalis Guenee (Pyralidae: Lepidoptera) under field conditions". Journal of Entomology and Zoology Studies 3.3 (2015): 292-295

45. Awal A., et al. Efficacy of seven insecticides on the larvae of brinjal shoot and fruit borer, Leucinodes orbonalis Guenee under laboratory condition. J. Patuakhali Sci. and Tech. Univ. 5.1 (2014): 37-43. 
46. Thapa RB. "An overview of pesticide pollution in Nepal". Nepalese Horticulture Society 1 (1997): 31-39.

47. Chakraborty K. "Effective Management of Scirpophaga incertulas Walker on rice crop during kharif season in West Bengal, India". American-Eurasian Journal of Agricultural and Environmental Sciences 12.9 (2012): 11761184.

48. Chakraborty S and Sarkar PK. "Management of Leucinodes orbonalis Guenee on eggplant during the rainy season in India". Journal of Plant Protection Research 51.4 (2011): 325328.

49. Sharma DR., et al. "Comparative potential of different botanicals and synthetic insecticides and their economics against Leucinodes orbonalis Guenee in eggplant". Journal of Plant Protection Research 52.1 (2012): 35-39.

50. Abrol DP and Singh JB. "Relative efficacy of some insecticides against brinjal fruit and shoot borer, Leucinodes orbonalis Guenee, and their impact on fruit yield". Journal of Asia-Pacific Entomology 6.1 (2003): 83-90.

Volume 3 Issue 9 September 2019

(C) All rights are reserved by Manish Gautam., et al. 